\title{
Working to Have a Normal Life With Cystic Fibrosis in an Adherence-Driven Health Care System
}

\author{
Marilyn Macdonald, Ariella Lang, Eileen Savage, Valerie Chappe, Andrea Murphy, Frances Gosse, \\ and Heather MacLean
}

\begin{abstract}
BACKGROUND: Adults with cystic fibrosis (CF) must continuously manage their condition, while working for a living, and want a normal life. Adherence rates to treatments/medications are less than optimal. Existing theory offers little to explain adherence rates. The purpose of this study was to develop a theory to further the understanding of how people with CF manage their condition in an adherence-driven health care system. METHODS: Constructivist Grounded Theory methodology was used to conduct 27 semistructured interviews with adults with $\mathrm{CF}$, family members, and health care providers. Data collection and analysis were simultaneous, using constant comparative methods, initial and focused coding, and category identification and reduction to develop a theory. RESULTS: Doing what works to balance life and CF is the theory generated from this study. The main concern of participants was to be seen as normal. The theory depicts what participants with CF and their family members do about their concerns and involves 4 interrelated processes: working overtime, receiving support, passing as normal, and facing disease progression. CONCLUSION: Participants did not relate to the term nonadherent; rather they described working overtime to manage $\mathrm{CF}$, to work, and to have a normal life. Health care provider and researcher perspectives on adherence differ from those of people with $\mathrm{CF}$. Engaging adults with $\mathrm{CF}$ and health care providers in a dialogue in which expectations are shared may lead to individualized treatment regimens that work, because adults with CF will do what works. Key words: grounded theory; cystic fibrosis; treatments; normal; adherence. [Respir Care 2019;64(8):945-952. (C 2019 Daedalus Enterprises]
\end{abstract}

\section{Introduction}

Developments in the treatment of cystic fibrosis (CF) have increased the lifespan of people living with the disease. ${ }^{1}$ Treatments associated with these developments necessitate carrying out the work of a daunting regimen ${ }^{2}$

Drs Macdonald, Lang, Chappe, Murphy, and Ms MacLean, are affiliated with Dalhousie University, Halifax, Nova Scotia, Canada. Dr Savage is affiliated with University College Cork, Cork, Ireland. Ms Gosse is affiliated with the Nova Scotia Health Authority, Halifax, Nova Scotia, Canada.

The authors have disclosed relationships with Canadian Institutes of Health (research grant 134451), Cystic Fibrosis Canada (Award ID\# 2995), and the Nova Scotia Lung Association.

Correspondence: Marilyn Macdonald PhD, School of Nursing, Faculty of Health, Dalhousie University, P.O. Box 15000 Halifax, Nova Scotia, Canada B3H 4R2. E-mail: marilyn.macdonald@dal.ca.

DOI: $10.4187 /$ respcare.06493 while trying to live a "normal" life. CF requires lifelong, clinical management that becomes increasingly complex as physical health deteriorates. Adherence to treatment regimens prescribed by health care providers is considered necessary to extending the lifespan.

Adherence is the extent to which a person's behavior, such as taking medication, following a diet, or executing lifestyle changes, corresponds with agreed-upon recommendations from the health care provider (World Health Organization, http://www.who.int/chp/knowledge/publications/ adherence_report/en, Accessed July 2, 2018). It is widely acknowledged that adherence to treatment by patients with CF is less than optimal and has negative health implications, such as an increased likelihood of experiencing a pulmonary exacerbation. ${ }^{3}$ Although adherence rates among adults with CF vary by treatment/medication, low rates remain consistent. For example, in 1996 Conway et $\mathrm{al}^{4}$ reported an overall adherence rate of $50 \%$. In subsequent studies, rates of adherence to treatment/medication were reported to be $88.2 \%$ for diges- 
tive enzymes, $61.8 \%$ for respiratory medications, and $41.2 \%$ for physiotherapy treatments. ${ }^{5}$ More recently, adherence rates for all pulmonary treatments have been reported at $40-57 \% .^{6}$ Following this trend is the 2015 report by Siracusa et $\mathrm{al}^{7}$ on adherence to ivacaftor use, which was at $61 \%$. When adherence is optimized in the $\mathrm{CF}$ population, there is a decrease in hospitalizations, slowing of disease progression, and improved patient safety.

Theories used to explain adherence or nonadherence point to an individual's behaviors positively or negatively. ${ }^{8-12} \mathrm{Re}-$ cent systematic reviews of theories used to predict medication adherence report modest effectiveness of any single theory. ${ }^{13,14}$ In 2010, Greenop et al ${ }^{15}$ advanced the notion of understanding behavior rather than focusing on correcting individual behavior. Although the body of work in this area is instructive to help understand predictors of adherence, it lacks the perspectives of those living with CF and their families. The 2018 ECFS Best Practice Guidelines ${ }^{16}$ call for partnering with patients to address adherence, yet they fall short on how to do this. The focus of this study was to generate a theory to further understand how individuals with $\mathrm{CF}$ and their families manage treatment regimens.

\section{Methods}

Constructivist Grounded Theory (CGT) was used to conduct this study. ${ }^{17}$ The design and method were informed by symbolic interactionism (SI), pragmatism and constructivism. Face-to-face interviews were conducted to obtain the perspectives of study participants that were generated and modified in the interaction process in keeping with SI. ${ }^{18}$ Pragmatism denotes that individuals do what works for them in their daily activities and in doing so come to understand what works. ${ }^{19,20}$ Constructivism assumes multiple realities of individuals and that the participant and the researcher co-construct the findings. ${ }^{17}$ Study participants were informed that this was a study to generate a theory to further understanding about adherence to treatment regimens. In CGT methodology the researcher asks open-ended questions to enable the participant to describe in their own words how they manage $\mathrm{CF}$ or work with those managing $\mathrm{CF}$. The interview guide contained a series of questions; however, the opening question, tell me how you manage your $\mathrm{CF}$ on a day to day basis, generated the rich description required to generate a theory and to avoid imposing researcher preconceptions on the data.

\section{Sample}

A total of 27 semistructured individual interviews were conducted. The sample consisted of 14 individuals with CF, 7 family members ( 5 spouses, 1 parent, 1 sib-

\section{QUICK LOOK}

\section{Current knowledge}

Rates of adherence to treatments/medications vary considerably for patients with cystic fibrosis. Adherence is considered predictive of exacerbation of infection and disease progression.

\section{What this paper contributes to our knowledge}

Doing what works to balance life and CF is the theory generated from this study. The theory involves four interrelated processes: working overtime, receiving support, passing as normal, and facing disease progression. The theory depicts what adults with $\mathrm{CF}$ do to be seen as normal.

ling), and 6 health care providers ( 2 nurses, 1 pharmacist, 1 dietitian, 1 social worker, and 1 psychologist). Table 1 describes the participants with $\mathrm{CF}$, all of whom attended a regional $\mathrm{CF}$ clinic staffed by a multidisciplinary health care team. The clinic coordinator informed patients about the study and provided the contact information. The sample size in this study is in keeping with that of Constructivist Grounded Theory. ${ }^{17}$ Ethical approval was obtained from the Capital District Health Authority. All participants gave written consent.

\section{Data Collection and Analysis}

Data collection and analysis were simultaneous, beginning with initial coding and followed by focused coding. Initial coding meant generating codes identifying action and interaction in the data, grouping these codes into categories (ie, focused codes), and then generating a set of concepts from the categories to constitute a theory. In this process the researcher identified the main concern of the participants with $\mathrm{CF}$, and the concepts depict what the participants do about the concern.

Data saturation was achieved with the construction of a set of robust categories. ${ }^{17}$ After coding and analysis of 5 interviews, a set of categories was developed. These categories were then used to do focused coding, ie, as coding continued, the codes fit the categories already developed. Some collapsing and re-naming of categories occurred as the theory was developed. The categories represent the codes and are the concepts of the theory. As the coding of interviews continued, there was no need for additional categories, and the data were deemed saturated. This determination is normally made in 20-30 interviews. 


\section{Living WiTh CF}

Table 1. Characteristics of Participants With Cystic Fibrosis

\begin{tabular}{lc}
\hline \multicolumn{1}{c}{ Characteristics } & Participants, $n$ \\
\hline Age, y & \\
$18-25$ & 0 \\
$25-30$ & 2 \\
$30-50$ & 9 \\
$\geq 50$ & 3 \\
Education & \\
$\quad<$ High school & 1 \\
High school & 5 \\
Post-secondary & 7 \\
Graduate degree & 1 \\
Employment & \\
Full-time & 7 \\
Part-time & 2 \\
Intermittent & 2 \\
Retired due to health & 3 \\
Province of residence (Canada) & \\
Nova Scotia & 10 \\
New Brunswick & 3 \\
Prince Edward Island & 1 \\
\hline
\end{tabular}

\section{Results}

Doing what works to balance life and CF is the grounded theory generated from this study. The main concern of the participants with CF was to be seen as normal. The theory depicts what participants with CF and their family members do about the concern, and this involved 4 interrelated processes: working overtime, receiving support, passing as normal, and facing disease progression (Fig. 1). To be able to breathe and to lead a life as near normal as possible, participants with CF and family members described life as continuously working overtime. Success in doing this work is contingent upon receiving support in various forms while passing as normal and facing disease progression. The 4 concepts that compose the theory are outlined. "Doing what works" for the participants with $\mathrm{CF}$ in this study refers to following a treatment regimen in a way that balances what makes them feel better yet helps them feel and be seen as a normal member of society.

\section{Working Overtime}

The concept of working overtime is intended to capture the extent of the work carried out by adults with $\mathrm{CF}$ and their family members in the management of the disease. The data were striking regarding the extent of the work and hours of commitment required every day to breathe, an act that passes unnoticed for most people. The work of breathing involved approximately $3-5 \mathrm{~h}$ of treatments each day, including aerosols in the morning and at night (including the preparation of medications and cleaning of equipment), using inhalers between aerosol treatments, taking enzymes with all food intake, having enzymes on hand at all times, insulin and diet management for those with CF-associated diabetes, and chest physiotherapy, all for an individual who wishes to be considered well and stable and who is gainfully employed with the duties and responsibilities of any other citizen. When infection develops, the work and time required to self-manage $\mathrm{CF}$ can double. The nature of the effort required in working overtime necessitates a balancing act to continue to meet employment requirements, and this drives adults with $\mathrm{CF}$ and their families to test the boundaries of what they really need to do with regard to medications and treatments to survive. One participant stated, "If I have a busy day, fortunately [inhalers] are quite quick. I can go to the break room and just have a Symbicort dose or a Ventolin dose. When I'm not feeling quite as well and I would rather have a Ventolin aerosol, it makes it a little bit trickier because I am kind of stuck with the [inhalers] to save time." Although the descriptions of the daily work of CF varied across participants, all of the participants clearly articulated the amount of work that they undertake to breathe with as much ease as possible. As explained by one participant, "Having CF is like having a job."

\section{Receiving Support}

Receiving support is multidimensional and contextual for adults with CF. Participants with CF, their family members, and their health care providers identified the need for and the importance of various forms of support. These forms of support include family/personal, CF community, $\mathrm{CF}$ health care clinic team, primary care providers, pharmacies, and financial.

Family/Personal Support. Participants with CF acknowledged all that their families did for them to reach adulthood, and in some cases parents and siblings continued to support the person with CF. In some cases, participants with CF managed independently, and in others a spouse was the primary source of support. Personal and family support included obtaining medications, assisting with physiotherapy, and providing financial support. Some participants managed their CF primarily on their own; as one male participant in his early 30s said, "I support myself." Others counted on their spouse to help them with CF; this included attending appointments, assisting with treatments, and earning the primary or sole family income (ie, the breadwinner role). In some ways, CF affects a spouse as much as the person with CF. In fact, some spouses work just as hard as their spouse with CF to keep the spouse going. One wife described the roles she plays and suggested that a lack of support for the caregiver leads to burnout: "So I feel I am the cheerleader, the 


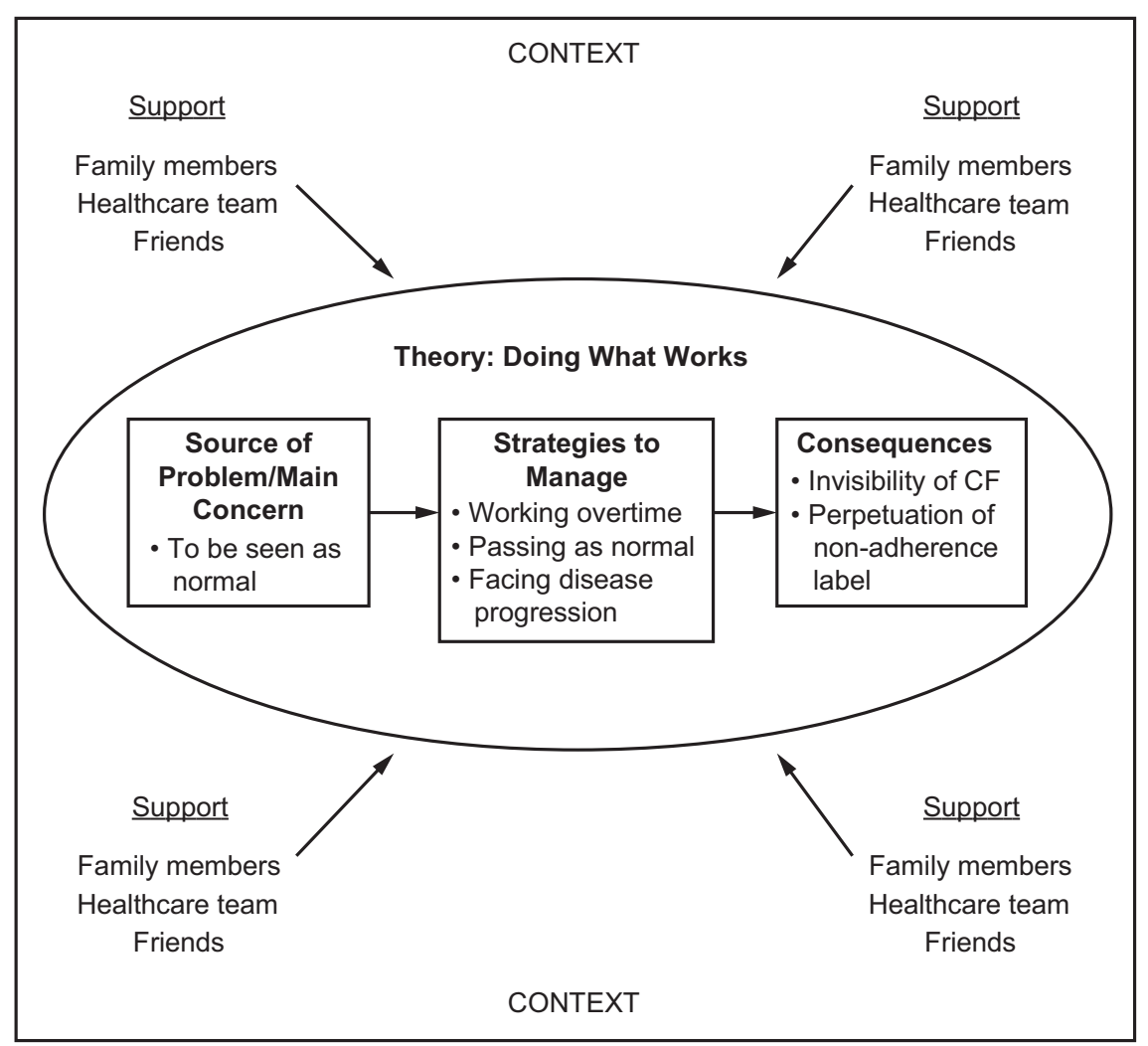

Fig. 1. The theory driver is shown at left, with the consequences of theory enactment at right. The theory plays out within a context, in which support at any level from others is critical. CF = cystic fibrosis.

nurse, and sometimes I'm the doctor. I feel like I am the lover, the wife, the mom." This spouse was very articulate about the ebb and flow of roles based on how ill their partner is at any given time. Spousal participants wondered how people with CF without a spouse or family support managed.

Some participants with CF acknowledged being supported by their friends. For example, when they socialized with friends, these friends made sure no one smoked around them and showed their understanding of CF: "You know, I have friends that own houses and they're like, "[Participant] is coming over. Everybody's got to smoke outside. Clear it out. He's on his way."

While people with $\mathrm{CF}$ are living longer, not all can maintain full-time employment throughout adulthood. This can mean giving up the breadwinner role. As one participant stated, "It's just, the financial part is the hard part sometimes because it's just... I know it's just financial but it's just, as a man, it's hard not to be able to work." Participants in spousal relationships, most notably men, felt inadequate as they were unable to contribute to the family income.

CF Community as Support. Historically, individuals living with $\mathrm{CF}$ and their families benefitted from a variety of opportunities to meet face-to-face and to forge valued friendships. More than 20 years ago, this form of support ceased with the recognition of the transfer and exchange of infection-producing organisms with severe consequences for lung health. In some cases, life-long friendships were forever changed. Social media has replaced face-to-face communication, but only some participants actively use social media to communicate with others; ie, some people with CF who do not use social media may have lost the support of other individuals with CF. Participants in general lamented the absence of the support that faceto-face contact affords.

Family members also felt cut off from support groups. One mother of an adult man with CF felt that she had considerable knowledge about raising children with $\mathrm{CF}$, information that other parents could benefit from, but she did not know how to contact other parents. She wanted to share " $[\mathrm{t}]$ he expertise that [she had] learned over the years or just the support. Saying, hey, listen, you know, it might be bad today, but tomorrow will be a little better."

CF Health Care Team. Having the support of a knowledgeable health care team with expertise in $\mathrm{CF}$ was considered a facilitator to living with CF. Participants praised the regional CF clinic team and other health workers such 
as pharmacists. One health professional interviewed noted that some patients develop a special bond with a certain team member and felt comfortable telling them about issues they were struggling with, such as anxiety or depression: "They all seem to have one team member that they connect more with for whatever reason. I find a lot of them will bring that up, or bring up how they feel. Especially if one of them has passed away and the others know, then often in clinic that will come up. And usually it's scaring them, and so I find a lot of them want to talk about it. And I guess we're safe because we know the disease and they can tell us those things." People with CF reported that, when they make decisions that are contrary to the treatment plan, they worry about disappointing the health care team; however, they believe the decisions that they are making are the best for their particular situation.

\section{Passing as Normal}

$\mathrm{CF}$ is a somewhat invisible disease; the average person would not know if someone had CF. Passing as normal means hiding CF from family members, employers, and co-workers. Hiding an illness speaks to public perceptions about illness and weakness that have implications for work (income) and relationships. Passing as normal requires effort and contributes to the concept of working overtime. It is important for health professionals to know that this work includes not only strict adherence to doing treatments, but also skipping treatments at work or when going out with friends to try to live what is perceived as a normal life. Alternatively, participants with CF expressed a strong desire for $\mathrm{CF}$ to be seen as normal and for more awareness from the general public (ie, perhaps with more awareness they would not have to work so hard to appear normal).

A recurring code in the data from adults with $\mathrm{CF}$ and health professionals was "hiding CF" to look "normal." The choice to hide CF is driven by the desire to avoid questions from family members and acquaintances, to get a job or a promotion, and, for some participants with children, to avoid burdening them with the knowledge of CF. The practice of hiding was highly variable in our participants, and this variation was contingent upon a participant's age, perceived work status, and social status. Participants who were 25-30 y old or 30-50 y old were reluctant to disclose having CF to employers, and those who were $30-50$ y old also struggled with disclosure to their children.

Hiding CF From Family Members. One participant was particularly "closeted" about having CF, hiding it from in-laws "because I just don't want them to get all over that." This participant carefully selected whom to tell while balancing privacy, career aspirations, and personal health.
No participants mentioned hiding $\mathrm{CF}$ from potential partners, although one reported avoiding marriage so as not to burden a partner with CF. Health care professionals confirmed their experiences related to hiding of CF. "Yes, we do have a number of [patients] that will not disclose. You know, they'll tell me, well, he likes me now but if I tell him I have CF, he might not. And they do have relationships where the other person can't cope with it. Which is sad."

For some participants with $\mathrm{CF}$, a happy consequence of living longer is having children. However, they are faced with how they will disclose CF to their children. Two participants recounted hiding their CF from their children and wondered about how to disclose. One said, "My children don't know I'm sick. They know daddy coughs and that he takes puffers. I will eventually tell them. But my children are pretty smart. So as they read on it, they're going to have questions of their own. I don't want to be looked at and looked down on or felt sorry for. That's my thing with CF." Another participant expressed uncertainty about how to tell a child about CF: "My 8-year-old daughter doesn't know anything about $\mathrm{CF}$, only what she sees. We don't know how to approach it, so we don't really say too much."

Strongly linked to the core category of "Doing what works," participants expressed a desire to be seen as "normal, healthy, and productive" members of society. Provider participants reported seeing persons with $\mathrm{CF}$ going to great lengths to hide their illness from others to avoid any stigma or ramifications (particularly in work settings) that may interfere with a career or fitting in with friends. Participants in our study mirrored this to some degree, with more focus on how they contribute and are productive members of society. A greater fear among the male participants was being viewed as a sick person. Participants carefully reflected on how, when, and to whom they disclose their illness, including their children.

Hiding CF at Work. Individuals try to present themselves in the best possible light at work, and the competitive environment of the workplace may mean illness looks like a threat to productivity. The participants, including health care professionals, provided many examples illustrating the degree to which $\mathrm{CF}$ is hidden in the workplace. Health care professionals explained that, in their experience, individuals with $\mathrm{CF}$ usually do not volunteer information regarding $\mathrm{CF}$ to employers in the short term. Health care professionals spoke of patients who hide CF during job interviews, recounting the story of a man who said he had asthma because he was afraid it would hurt his career if others knew he had CF. His story is similar to a statement made by one of our participants: he lets others assume he has asthma because many people find that easier to understand, and, unlike CF, asthma is seen as a man- 


\section{Living WiTh CF}

ageable disease. Another participant recounted telling people at work that it was a cold if anyone asked about a cough. However, eventually this participant requested reduced work hours, and the supervisor has been very supportive since being informed of the CF diagnosis.

In general, participants with $\mathrm{CF}$ varied in the extent to which they revealed their CF. They reported getting more comfortable over time with $\mathrm{CF}$, demonstrating this by openly taking enzymes and inhaled medications because these are actions commonly seen in public. All but 2 participants were reluctant to do aerosol treatments in public. Consuming nutritional supplements was described as easier now because these drinks are used by a variety of individuals and are considered mainstream. Participants with a strong social support system and those who felt secure in their chosen employment were more likely to consider disclosing their CF. Those who fully disclosed did so because they wanted to raise awareness about CF and to contribute to greater acceptance of people with CF.

To be seen as normal was important for our participants with CF so that they could get and keep a job, and avoid explaining their illness. However, we were reminded by our participants that, despite the progress made in the treatment and management of $\mathrm{CF}$, most individuals are facing disease progression. Disease progression is ultimately driving disclosure.

\section{Facing Disease Progression}

In the not too distant past, having CF meant a shortened life span, and many children did not reach adulthood. With improved treatments, today people with CF live longer, although the disease still progresses as they age. Participants invariably explained that, over time, they noticed they could no longer maintain the level of productivity they once enjoyed in their work as well as in personal lives. In the analysis process, we coded this as "facing disease progression." This category easily relates to working overtime because participants gradually realized that, despite their best self-management efforts, they could not keep up as before.

Having lived with CF since birth, many accepted their disease progression because they recalled knowing they were not supposed to live to be $10 \mathrm{y}$ old, then $20 \mathrm{y}$ old, and then beyond. Contrary to patients' accounts of their work to manage $\mathrm{CF}$, health care provider participants reported that adults with $\mathrm{CF}$ understood their disease would progress and eventually lead to death, but that they could not accept this for their families. Health care providers reported that patients felt obliged to fight the disease for their family members, but in private they were ready to accept death. Part of the "working" is not just to stay alive, but working overtime to avoid upsetting their families. This category has an important sub-process conceptual- ized as "living beyond an expiry date." Not only have individuals with $\mathrm{CF}$ lived with being told they may not live beyond 5,10 , or $15 \mathrm{y}$, but now that they have, they realize they must make arrangements as they get older and prepare mentally for a time when they may need a lung transplant or receive disability benefits. Participants with $\mathrm{CF}$ depicted the work of managing $\mathrm{CF}$ and of doing what it takes to be seen as normal.

In living with $\mathrm{CF}$, disease progression is inevitable, and participants with $\mathrm{CF}$ and their family members often recounted milestones that marked life events they thought were not attainable because they would not live or be well enough to accomplish them (eg, marriage, having children, travel). They also described times, such as surviving a severe illness, that either encouraged them to work to survive or marked the onset of their disease progression. Many participants talked rationally and logically of death but held more concerns around disease progression and poor quality of life. In addition, as persons with CF live longer, worries have shifted from staying alive to career, saving money, retirement, telling children about $\mathrm{CF}$, and possible adverse effects of their medication regimen (particularly a reliance on antibiotics).

Noticing disease progression ranged from not being able to keep up with friends when playing sports, to not bouncing back from illness as quickly as one did in the past, to having to stop work and other activities. Participants with $\mathrm{CF}$ expressed frustration at the progression, knowing nothing could be done to prevent progression. Health care providers shared a unique perspective because patients sometimes tell them things they do not want loved ones to hear, such as "that they are tired of fighting CF but only keep going for the sake of the family," showing again that $\mathrm{CF}$ does not just affect the person with the illness. One health care professional also saw how disease progression put emotional and financial stress on a relationship. No longer being able to work and provide for the family was another worry that accompanied CF progression and was captured by the partner of a participant with CF: "Maybe somebody doesn't recognize that nursing [my husband] for 9 straight weeks, and taking on a full-time job, and being a mother, actually drives the caregiver... into the ground."

Participants recounted compelling stories of disease progression that generated this robust category, with each narrative building on the previous. One participant noted, "Well, I don't know the rules surrounding that [assisted death] with CF, but if I can't take care of myself, such that I need to rely on someone else to do it for me, I think that's where I would start to look at the options of, like, doctorassisted suicide ... like, quality over quantity. I'm not interested in, like, living in a hospital bed for a chronic period of time." 


\section{Living WiTh CF}

\section{Discussion}

The reasons as to why individuals with CF do not adhere to prescribed regimens include feeling well, work demands, interference with social life, embarrassment, treatment burden, forgetting, absence of perceived benefit, fatigue, depression, and anxiety. ${ }^{21,22}$ Although recruitment materials and consent forms for this study used the language of adherence, this was not part of the language used by individuals with $\mathrm{CF}$ and their families. Participants with $\mathrm{CF}$ described working constantly to balance $\mathrm{CF}$ with leading a normal life. These individuals did not portray themselves as nonadherent; they fully appreciated the $\mathrm{CF}$ clinic team and hated to disappoint them, yet pragmatically they saw themselves as doing what treatments they could while going to work and leading a life like everyone else.

Adherence is a term constructed by researchers and health care providers to express what a patient fails to do and situates responsibility within the patient. The main concern of the participants of our study was to be seen as normal. This evidence is not new, ${ }^{23}$ yet inattention to this by researchers and health care providers may contribute to the perpetuation of the construction of adherence. Passing as normal involved hiding $\mathrm{CF}$ from family members as well as employers, and this could be considered stressprovoking. However, participants with CF described this as part of the work required to be seen as normal. Patients are known to take medication holidays in an effort to be normal. ${ }^{22}$ Treatment effectiveness studies are commonly based on adherence rates of $>90 \% .{ }^{24}$ Has consideration been given to lower rates, opening the door to some flexibility for patients?

This Grounded Theory study was underpinned by a pragmatic perspective, meaning that individuals can figure out what works for them and operate accordingly in everyday life. The data are evidence of this, as participants told us how much work it was to manage $\mathrm{CF}$, how they made decisions about treatments they could skip based on perceived benefit, and that they do this to fit CF with life and trying to be normal. Decision-making is based on what individuals with $\mathrm{CF}$ believe will work to achieve balance with CF management and day-to-day life. For example, using an inhaler takes much less time than an additional nebulizer treatment in the workplace, and going to the gym is equated with chest physiotherapy. These decisions help those with CF feel normal in the workplace and outside the workplace.

Individuals with $\mathrm{CF}$ value the $\mathrm{CF}$ clinic team and their approval and support highly. Open dialogue about how CF is self-managed is essential to the provider-patient relationship and to what self-care choices people with $\mathrm{CF}$ make. These patients seek some sense of approval and recognition of what they are doing and advice on what may be modifiable, which may seem contradictory in the face of disease progression.

Facing disease progression is one concept of this theory not typically described in the CF literature. It is reasonable to consider that this concept is closely related to the other concepts. For example, participants with CF expressed how much work $\mathrm{CF}$ is and, despite this, also clearly explained how they could tell that the disease was progressing. Doing the work of managing $\mathrm{CF}$ and keeping ahead of the disease could be seen as a motivator to follow the treatment regime, whereas doing the work while facing disease progression is likely very challenging. Knowledge that those with CF constantly face disease progression underscores the importance of the support from health care providers, families, and all involved.

\section{Clinical Implications/Suggestions}

Although clinical practice guidelines are considered the accepted standard in clinical care, the life of the individual has not traditionally been part of guideline development. This situation is changing, and evidence now questions the suitability of guidelines without patient input. ${ }^{25}$ As guidelines for the care of individuals with $\mathrm{CF}$ are updated and developed, the opportunity exists to involve those with $\mathrm{CF}$ and to develop guidelines that have a greater likelihood to work for the target group.

The plan of care for the individual with $\mathrm{CF}$ is developed by a multidisciplinary care team, with the patient and family as part of the team. Patients and families need to feel comfortable to share with the team what works for them and what gets in the way of carrying out the plan. When team members are aware of individual factors that may interfere with the plan, a discussion on options is possible. Team members need to have the conversation with the patient to dissect what the care team may see as nonadherence to determine if the plan as outlined is reasonable or if tailoring the plan to the individual is needed.

The provision of medications and supplies for CF management vary by jurisdiction in Canada; eg, one province provides comprehensive coverage, while 2 provinces had some restrictions on coverage. Comprehensive coverage lifts cost-associated barriers to following treatment plans and contributes to the likelihood of adhering to a plan of care and to longevity.

The preference for inhalers over nebulizers in attempting to minimize downtime in the workplace and disease management time at home is instructive to the pharmaceutical and medical devices communities. If the time needed to effectively manage the disease was expected to be minutes per day as opposed to hours per day, this may also help people with $\mathrm{CF}$ optimally self-manage their disease. 


\section{Living WiTh CF}

The definition of adherence should be revised to include the patient's voice. This will necessitate reflection on what is clinically deemed adherence, as well as collaboration with adults with CF to arrive at plans of care that optimize the likelihood of adherence. This may in turn mitigate the unilateral application of the use of the term nonadherence.

\section{Limitations}

We have identified 2 important limitations in our study. First, our study was notable for the absence of participants in the 18-25 years age range. Despite recruitment attempts, the reason provided was not wanting to talk about $\mathrm{CF}$, thus the perspectives of this age group are not reflected. Second, although the study sample size was 27 participants and a theory was generated, a larger and more varied sample would contribute to theory excellence and transferability for the findings of qualitative research to a wider population.

\section{Conclusion}

Adults with $\mathrm{CF}$ perceive themselves as working overtime to manage their disease, yet the CF literature continues to report significant levels of nonadherence. The theory generated in this study suggests that a disconnect exists between the perceptions of adults with $\mathrm{CF}$, the work they do to pass as normal, and the evidence related to adherence to treatment regimens. Adults with $\mathrm{CF}$ value all forms of support highly, in particular that of the $\mathrm{CF}$ health care team; individuals with $\mathrm{CF}$ do not wish to disappoint the health care team, but they will make changes in their health plan to try to feel normal. The work they do to manage their $\mathrm{CF}$ and the support they receive does not change the fact they want to be seen as normal despite facing disease progression. This theory is intended to further the understanding of adherence from the perspectives of those with $\mathrm{CF}$ as well as health care providers.

\section{REFERENCES}

1. Stephenson AL, Stanojevic S, Sykes J, Burgel PR. The changing epidemiology and demography of cystic fibrosis. Presse Med 2017; 46(6):e87-e95.

2. Sawicki GS, Sellers DE, Robinson WM. High treatment burden in adults with cystic fibrosis: Challenges to disease self-management. J Cyst Fibros 2009;8(2):91-96.

3. Eakin MN, Bilderback A, Boyle MP, Mogayzel PJ, Riekert KA. Longitudinal association between medication adherence and lung health in people with cystic fibrosis. J CystFibros 2011;10(4):258-264.

4. Conway SP, Pond MN, Hamnett T, Watson A. Compliance with treatment in adult patients with cystic fibrosis. Thorax 1996;51(1):29-33.

5. Arias Llorente RP, Bousoño García C, Díaz Martín JJ. Treatment compliance in children and adults with Cystic Fibrosis. J Cyst Fibros 2008;7(5):359-367.
6. Quittner AL, Zhang J, Marynchenko M, Chopra PA, Signorovitch J, Yushkina Y, Riekert KA. Pulmonary medication adherence and health-care use in cystic fibrosis. Chest 2014;146(1):142-151.

7. Siracusa CM, Ryan J, Burns L, Wang Y, Zhang N, Clancy JP, Drotar D. Electronic monitoring reveals highly variable adherence patterns in patients prescribed ivacaftor. J Cyst Fibros 2015;14(5):547-548.

8. Ajzen I. The theory of planned behavior. Organ Behav Hum Decis Process 1991;50(2):179-211.

9. Hochbaum GM. Public participation in medical screening programs: a socio-psychological study. Washington, DC: U.S. Department of Health, Education and Welfare; 1958.

10. Leventhal H, Nerenz D, Steele DJ. Illness representations and coping with Health threats. In: Baum A, Singer J, editors. A handbook of psychology and health. Hillsdale, NJ: Erlbaum; 1984. p. 219-252.

11. Orem DE, Taylor SG, Renpenning KM. Nursing : concepts of practice. 6th ed. St. Louis, MO; Toronto, CA: Mosby; 2001.

12. Parcel GS, Swank PR, Mariotto MJ, Bartholomew LK, Czyzewski DI, Sockrider MM, et al. Self-management of cystic fibrosis: A structural model for educational and behavioral variables. Soc Sci Med 1994;39(9):1307-1315.

13. Conn VS, Enriquez M, Ruppar TM, Chan KC. Meta-analyses of theory use in medication adherence intervention research. Am J Health Behav 2016;40(2):155-171.

14. Holmes EAF, Hughes DA, Morrison VL. Predicting adherence to medications using health psychology theories: A systematic review of 20 years of empirical research. Value Heal 2014;17(8):863-876.

15. Greenop D, Glenn S, Ledson M, Walshaw M. Self-care and cystic fibrosis: A review of research with adults. Heal Soc Care Community 2010;18(6):653-661.

16. Castellani C, Duff AJA, Bell SC, Heijerman HGM, Munck A, Ratjen F, et al. ECFS best practice guidelines: the 2018 revision. J Cyst Fibros 2018;17(2):153-178.

17. Charmaz K. Constructing grounded theory: a practical guide through qualitative analysis. Thousand Oaks, CA: Sage 2006.

18. Blumer H. The Methodological Position of Symbolic Interactionism. In: Symbolic Interactionism: Perspective and Method. Englewood Cliffs, NJ: Prentice-Hall; 1969.

19. Magee GA, Magee GA. Hegel and the hermetic tradition. Ithaca, NY: Cornell University Press; 2001.

20. Popkin RH, Stroll A. Philosophy made simple. New York, NY: Doubleday; 1993.

21. Bregnballe V, Schiøtz PO, Lomborg K. Parenting adolescents with cystic fibrosis: The adolescents' and young adults' perspectives. Patient Prefer Adherence 2011;5:563-570.

22. George M, Rand-Giovannetti D, Eakin MN, Borrelli B, Zettler M, Riekert KA. Perceptions of barriers and facilitators: Self-management decisions by older adolescents and adults with CF. J Cyst Fibros 2010;9(6):425-432.

23. Macdonald M, Martin-Misener R, Helwig M, Smith LJ, Godfrey CM, Curran J, Murphy A. Experiences of adults with cystic fibrosis in adhering to medication regimens: a qualitative systematic review. JBI database Syst Rev Implement reports 2016;14(5):258-285.

24. Whiting P, Al Maiwenn, Burgers L, Westwood M, Ryder S, Hoogendoorn $\mathrm{M}$, et al. Ivacaftor for the treatment of patients with cystic fibrosis and the G551D mutation: A systematic review and costeffectiveness analysis. Health Technol Assess (Rockv) 2014;18(18): $1-106$.

25. Armstrong MJ, Mullins CD, Gronseth GS, Gagliardi AR. Impact of patient involvement on clinical practice guideline development: a parallel group study. Implementation Science 2018;13:55. 